\title{
Reference frame for home pulse pressure based on cardiovascular risk in 6470 subjects from 5 populations
}

\author{
Lucas S Aparicio ${ }^{1}$, Lutgarde Thijs ${ }^{2}$, Kei Asayama ${ }^{2,3}$, Jessica Barochiner ${ }^{1}$, José Boggia ${ }^{4}$, Yu-Mei Gu ${ }^{2}$, \\ Paula E Cuffaro', Yan-Ping Liu ${ }^{2}$, Teemu J Niiranen ${ }^{5,6}$, Takayoshi Ohkubo ${ }^{3,7}$, Jouni K Johansson ${ }^{5}$, \\ Masahiro Kikuya $^{8}$, Atsushi Hozawa ${ }^{8}$, Ichiro Tsuji ${ }^{9}$, Yutaka Imai ${ }^{3}$, Edgardo Sandoya ${ }^{10}$, George S Stergiou ${ }^{11}$, \\ Gabriel D Waisman ${ }^{1}$ and Jan A Staessen ${ }^{2,12}$ on behalf of the International Database \\ on HOme blood pressure in relation to Cardiovascular Outcome (IDHOCO) Investigators
}

The absence of an outcome-driven reference frame for self-measured pulse pressure (PP) limits its clinical applicability. In an attempt to derive an operational threshold for self-measured PP, we analyzed 6470 participants (mean age 59.3 years; $56.9 \%$ women; $22.5 \%$ on antihypertensive treatment) from 5 general population cohorts included in the International Database on HOme blood pressure in relation to Cardiovascular Outcome. During 8.3 years of follow-up (median), 294 cardiovascular deaths, 393 strokes and 336 cardiac events occurred. In 3285 younger subjects ( $<60$ years), home PP only predicted all-cause and cardiovascular mortality $(P \leqslant 0.036)$, whereas in 3185 older subjects ( $\geqslant 60$ years) PP predicted total and cardiovascular mortality $(P \leqslant 0.0067)$ and all cardiovascular and coronary events $(P \leqslant 0.044)$. However, PP did not substantially refine risk prediction based on classical risk factors including mean blood pressure (generalized $R^{2}$ statistic $\leqslant 0.20 \%$ ). In older subjects, the adjusted hazard ratios expressing the risk in the upper decile of home PP ( $\geqslant 76 \mathrm{~mm} \mathrm{Hg}$ ) versus the average risk in whole population were 1.41 (95\% confidence interval, $1.09-1.81 ; P=0.0081)$ for all-cause mortality, $1.62(1.11-2.35$; $P=0.012)$ for cardiovascular mortality and $1.31(1.00-1.70 ; P=0.047)$ for all fatal and nonfatal cardiovascular end points combined. The low number of events precluded an analysis by tenths of the PP distribution in younger participants. In conclusion, a home PP of $\geqslant 76 \mathrm{~mm} \mathrm{Hg}$ predicted cardiovascular outcomes in the elderly with the exception of stroke, whereas in younger subjects no threshold could be established.

Hypertension Research (2014) 37, 672-678; doi:10.1038/hr.2014.45; published online 20 March 2014

Keywords: cardiovascular diseases; epidemiology; home blood pressure; pulse pressure; thresholds

\section{INTRODUCTION}

Pulse pressure (PP), the difference between systolic and diastolic blood pressure, depends on left ventricular ejection, the elasticity of the central arteries, and the timing and intensity of the backward wave originating at reflection sites in the peripheral circulation. PP widens in the elderly, because with advancing age systolic blood pressure continues to rise, whereas the age-related increase in diastolic blood pressure levels off or even reverses in the fifth decade of life. ${ }^{1}$ Several studies showed that PP, derived from the conventionally measured blood pressure, predicts adverse outcomes in patients with cardiovascular $^{2}$ or renal disease ${ }^{3,4}$ as well as in populations. ${ }^{5-9}$ Compared with the conventionally measured blood pressure, selfmeasurement of blood pressure refines risk stratification. ${ }^{10}$ To our knowledge, only one population study examined the risk of stroke associated with the self-measured PP in Japanese. ${ }^{11}$ Moreover, current guidelines for the management of blood pressure do not propose

${ }^{1}$ The Servicio de Clínica Médica, Sección Hipertensión Arterial, Hospital Italiano de Buenos Aires, Buenos Aires, Argentina; ${ }^{2}$ Studies Coordinating Centre, Research Unit Hypertension and Cardiovascular Epidemiology, KU Leuven Department of Cardiovascular Sciences, University of Leuven, Leuven, Belgium; ${ }^{3}$ Department of Planning for Drug Development and Clinical Evaluation, Tohoku University Graduate School of Pharmaceutical Sciences, Sendai, Japan; ${ }^{4}$ Centro de Nefrología and Departamento de Fisiopatología, Hospital de Clínicas, Universidad de la República, Montevideo, Uruguay; ${ }^{5}$ Population Studies Unit, Department of Chronic Disease Prevention, National Institute for Health and Welfare, Turku, Finland; ${ }^{6}$ Department of Medicine, Turku University Hospital, Turku, Finland; 7 Department of Hygiene and Public Health, Teikyo University School of Medicine, Tokyo, Japan; ${ }^{8}$ Department of Preventive Medicine and Epidemiology, Tohoku Medical Megabank Organization, Tohoku University, Sendai, Japan; ${ }^{9}$ Department of Public Health, Tohoku University Graduate School of Medicine, Sendai, Japan; ${ }^{10}$ Department of Cardiology, Asociación Española Primera de Socorros Mutuos, Montevideo, Uruguay; ${ }^{11}$ Third Department of Medicine, Hypertension Center, University of Athens, Sotiria Hospital, Athens, Greece and ${ }^{12}$ Department of Epidemiology, Maastricht University, Maastricht, The Netherlands

Correspondence: Professor JA Staessen, Research Unit Hypertension and Cardiovascular Epidemiology, KU Leuven Department of Cardiovascular Sciences, Studies Coordinating Centre, University of Leuven, Campus Sint Rafaël, Kapucijnenvoer Block D, Box 7001, 3000 Leuven, Belgium.

E-mail: jan.staessen@med.kuleuven.be

Received 11 August 2013; revised 15 November 2013; accepted 21 December 2013; published online 20 March 2014 
outcome-driven thresholds for $\mathrm{PP}^{12,13}$ We therefore assessed the predictive value of the self-measured home PP in 6470 people randomly recruited from 5 populations and enrolled in the International Database of HOme blood pressure in relation to Cardiovascular Outcome (IDHOCO).

\section{METHODS}

\section{Study population}

The construction of the IDHOCO database has been described previously. ${ }^{14}$ At the time of writing this report, we collected data from 7 prospective population studies (8912 subjects). All studies received ethical approval. For the present analysis we discarded two cohorts, because data on cause-specific mortality were still being collected, ${ }^{15}$ or because the study included patients instead of a general population sample. ${ }^{16}$ Of the 6753 remaining participants, we excluded 283 because $<2$ home blood pressure readings $(n=18)$ or $<2$ conventional blood pressure readings $(n=267)$ were available. Therefore, the number of participants analyzed totaled 6470, comprising 2520 inhabitants of Ohasama, Japan; ${ }^{17} 2075$ Finns representing a nationwide sample; ${ }^{18} 811$ inhabitants of the Tsurugaya district, Sendai, Japan; ${ }^{19} 399$ inhabitants of Montevideo, Uruguay ${ }^{20}$ and 665 inhabitants of Didima, Greece. ${ }^{21}$ We categorized participants into Whites (inhabitants of Finland, Didima and Montevideo) and Asians (inhabitants of Sendai and Ohasama).

\section{Blood pressure measurement}

Clinic blood pressure was measured with a standard mercury sphygmomanometer or an automated device (Elquest USM-700F (Elquest Corporation, Chiba, Japan), Omron HEM-705CP or Omron Form ABI/PWV (Omron Healthcare Co., Ltd, Kyoto, Japan)), using the appropriate cuff size. The average of the first two office blood pressure readings was used for analysis.

Participants recorded their home blood pressure after $2-5 \mathrm{~min}$ of rest in the sitting position with validated oscillometric devices (Omron HEM-401C, Omron HEM-722C, Omron HEM-747, Omron HEM-705CP or SpaceLabs 90207, Spacelabs Healthcare, Snoqualmie, WA, USA), using the appropriate cuff size. The median number of home blood pressure measurements ranged from 2 in Montevideo ${ }^{20}$ to 52 in Ohasama. ${ }^{17}$ The mean of all available measurements was used for analysis. Home PP was systolic minus diastolic blood pressure. Mean arterial pressure was diastolic blood pressure plus one third of PP. Hypertension was a home blood pressure of at least $135 \mathrm{~mm} \mathrm{Hg}$ systolic or $85 \mathrm{~mm} \mathrm{Hg}$ diastolic ${ }^{13}$ or use of antihypertensive drugs.

\section{Other measurements}

We used the baseline questionnaires originally administered in each cohort to obtain information on each participant's medical history, intake of medications and smoking and drinking habits. Subjects using any amount of tobacco or alcohol in the period of the baseline examination were classified as smokers or drinkers. Body mass index was body weight in kilograms divided by height in meters squared. Previous cardiovascular disease included cardiac and cerebrovascular disorders and peripheral vascular disease. Serum cholesterol and blood glucose were determined by automated enzymatic methods on venous blood samples. Diabetes mellitus was a self-reported diagnosis, a fasting or random blood glucose level of $7.0 \mathrm{mmoll}^{-1}\left(126 \mathrm{mg} \mathrm{dl}^{-1}\right)$ or $11.1 \mathrm{mmoll}^{-1}$ $\left(200 \mathrm{mg} \mathrm{dl}^{-1}\right)$ or higher, ${ }^{22}$ or use of antidiabetic drugs.

\section{Ascertainment of events}

We ascertained vital status and incidence of fatal and non-fatal diseases from the appropriate sources in each country, as described in detail in a previous publication. ${ }^{18}$ Fatal and non-fatal stroke did not include transient ischemic attacks. Coronary events encompassed death because of ischemic heart disease, sudden death, non-fatal myocardial infarction, and surgical and percutaneous coronary revascularization. Cardiac events comprised coronary end points, fatal and non-fatal heart failure, pacemaker implantation and other cardiac deaths. The composite cardiovascular end point included cardiovascular mortality, cerebrovascular and cardiac endpoints. We summarized the ascertainment and definition of events in each of the cohorts in
Supplementary Table S1. In all outcome analyses, we only considered the first event per participant within each category.

\section{Statistical analyses}

For database management and statistical analysis, we used the SAS software, version 9.3 (SAS Institute, Cary, NC, USA). For comparison of means and proportions, we applied the large sample $z$ test and the $\chi^{2}$ statistic, respectively. Statistical significance was an $\alpha$-level of $<0.05$ on two-sided tests. As described previously, ${ }^{14}$ we interpolated missing values of body mass index $(n=382)$ and serum cholesterol $(n=133)$ from the regression slope on age after stratification for cohort and sex. In subjects with unknown smoking habits $(n=19)$ and drinking status $(n=1216)$, we set the design variable to the cohort- and sex-specific mean of the codes $(0,1)$. In the Didima cohort $(n=665)$, we extrapolated cholesterol values and drinking habits by sex and age, from data provided by large population cohorts living in a similar geographical area. ${ }^{23,24}$

We used Cox regression to compute hazard ratios (HRs). We checked the proportional hazards assumption and the functional forms of the covariables by the Kolmogorov-type supremum test, as implemented in the PROC PHREG procedure of the SAS software. Because the role of PP changes with age, we stratified all analyses by age $60 . .^{25}$ To compute HRs in tenths of the PP distribution, we applied the deviation from mean coding. ${ }^{26}$ This approach expresses the risk in each tenth relative to the overall risk in the whole study population and allows computing $95 \%$ confidence intervals (CIs) for the HRs in all tenths without definition of an arbitrary reference group. The HRs for PP and mean arterial pressure analyzed as continuous variables were standardized and express the risk associated with a 1-s.d. increase in the independent variable. We tested heterogeneity in the HRs across subgroups by introducing the appropriate interaction term in the Cox model. The improvement in prediction performance gained by adding PP to a model already including the conventional risk factors was assessed by the net reclassification improvement, ${ }^{27}$ the integrated discrimination improvement ${ }^{27}$ and Harrell's $c$-statistic. ${ }^{28}$ We applied the generalized $R^{2}$ statistic to assess the risks additionally explained by PP over and beyond mean arterial pressure and other covariables. ${ }^{29}$ We stratified Cox models for cohort and adjusted HRs for baseline characteristics including sex, age, body mass index, current smoking, alcohol intake, serum cholesterol, history of cardiovascular disease, diabetes mellitus, antihypertensive treatment, home pulse rate and mean blood pressure.

\section{RESULTS}

\section{Characteristics of participants}

The whole study population comprised 3139 Europeans (48.5\%) and 3331 Asians (51.5\%). Of the 6470 participants, 3680 were women (56.9\%), 2786 (43.1\%) had hypertension on home blood pressure measurement and $1452(22.4 \%)$ were taking blood pressure-lowering drugs. Mean ( \pm s.d.) age was $59.3 \pm 13.5$ years. In the whole study population, home blood pressure averaged $127.2 \pm 18.2 \mathrm{~mm} \mathrm{Hg}$ systolic, $76.1 \pm 10.0 \mathrm{~mm} \mathrm{Hg}$ diastolic, $51.1 \pm 12.9 \mathrm{~mm} \mathrm{Hg}$ for PP and $93.1 \pm 11.9 \mathrm{~mm} \mathrm{Hg}$ for mean arterial pressure. At enrollment, 1352 participants $(20.9 \%)$ were current smokers and $2721(51.8 \%)$ reported intake of alcohol. Table 1 shows the characteristics of the participants by age group and sex.

\section{Analysis of younger participants}

Incidence of end points. Among 3285 younger subjects, median followup was 8.3 years (5th-95th percentile interval, 7.2-16.8 years). Over 32671 person-years of follow-up, 149 participants died (4.6 per 1000 person-years) and 161 experienced a fatal or non-fatal cardiovascular complication (5.0 per 1000 person-years). The cause of death was cardiovascular in 41 participants, non-cardiovascular in 105 and renal failure in 3. Considering cause-specific first cardiovascular events, 73 subjects experienced a fatal or non-fatal stroke (14 and 59, respectively) and 90 subjects had a fatal or non-fatal cardiac event (22 and 68). 
Table 1 Baseline characteristics of participants by age group

\begin{tabular}{lcc}
\hline Characteristic & $<60$ years & $\geqslant 60$ years \\
\hline Number of subjects (\%) & 3285 & 3185 \\
Women & $1871(56.9)$ & $1809(56.8)$ \\
Asian & $1225(37.3)$ & $2106(66.1)$ \\
Smokers & $873(26.6)$ & $479(15.1)$ \\
Drinking alcohol & $1540(58.8)$ & $1181(44.8)$ \\
Hypertension & $882(26.9)$ & $1904(59.8)$ \\
On antihypertensive treatment & $389(11.9)$ & $1063(33.4)$ \\
Diabetes mellitus & $170(5.2)$ & $376(11.8)$ \\
Cardiovascular disorders & $125(3.8)$ & $539(16.9)$ \\
Mean ( \pm s.d.) characteristic & & \\
Age, years & $48.3(8.6)$ & $70.5(6.7)$ \\
Body mass index, kg m ${ }^{-2}$ & $25.7(4.2)$ & $25.2(4.3)$ \\
Conventional blood & & \\
pressure, mm Hg & & $140.6(20.3)$ \\
Systolic & $127.5(18.4)$ & $79.3(11.6)$ \\
Diastolic & $78.8(11.9)$ & $61.3(15.1)$ \\
Pulse pressure & $48.7(12.9)$ & $99.7(13.3)$ \\
Mean arterial pressure & $95.0(13.1)$ & \\
Self-recorded pressure & & $77.1(9.5)$ \\
Systolic & $120.1(15.7)$ & $57.4(13.4)$ \\
Diastolic & $75.2(10.4)$ & $96.2(11.2)$ \\
Pulse pressure & $44.9(8.9)$ & $67.5(8.9)$ \\
Mean arterial pressure & $90.1(11.7)$ & \\
Self-recorded pulse rate, & $70.7(9.0)$ & \\
beats min ${ }^{-1}$ & & $11.1)$ \\
Serum cholesterol, mmol I-1 & $5.57(1.1)$ & \\
\hline
\end{tabular}

Hypertension was a home blood pressure of at least $135 \mathrm{~mm} \mathrm{Hg}$ systolic or $85 \mathrm{~mm} \mathrm{Hg}$ diastolic or use of antihypertensive drugs. Diabetes mellitus was a self-reported diagnosis, a fasting or random blood glucose level of $7.0 \mathrm{mmoll}^{-1}\left(126 \mathrm{mgdl}^{-1}\right)$ or $11.1 \mathrm{mmoll}^{-1}\left(200 \mathrm{mg} \mathrm{dl}^{-1}\right)$ or higher, or use of antidiabetic drugs. All differences between age groups were significant $(P<0.0001)$ with the exception of conventional diastolic blood pressure $(P=0.10)$ and the proportion of women $(P=0.90)$.
Risk associated with home PP. The association between outcome and PP did not deviate significantly from log linearity $(P \geqslant 0.092)$. Table 2 shows the standardized HRs associated with home mean blood pressure and home PP. With adjustments applied for cohort, sex, age, body mass index, smoking and drinking, serum cholesterol, home pulse rate, history of cardiovascular disease, diabetes mellitus and antihypertensive treatment, the home PP significantly predicted all outcomes, except fatal and non-fatal stroke. After further adjustment for mean arterial pressure, PP only predicted total mortality (HR, 1.24; 95\% CI, 1.01-1.51; $P=0.036)$ and cardiovascular deaths (HR, 1.47; CI, 1.03-2.10; $P=0.033$ ). The results of a similar analysis on the association between outcome and home PP adjusted for home systolic blood pressure are shown in Supplementary Table S2. The small number of events precluded an analysis by tenths of the home PP distribution in younger participants.

\section{Analysis of older participants}

Incidence of end points. Among 3185 older subjects, median followup was 8.2 years (5th-95th percentile interval, 7.2-16.8 years). Over 26655 person-years of follow-up, 663 participants died (24.9 per 1000 person-years) and 555 experienced a fatal or non-fatal cardiovascular complication (22.0 per 1000 person-years). The cause of death was cardiovascular in 253 participants, non-cardiovascular in 395, renal failure in 10 and unknown in 5. Considering cause-specific first cardiovascular events, 320 subjects experienced a fatal or non-fatal stroke (64 and 256, respectively) and 246 subjects had a fatal or nonfatal cardiac event (127 and 119).

Risk associated with home PP. In older subjects (age $\geqslant 60$ years), the association between outcome and PP did not deviate significantly from log linearity $(P \geqslant 0.15)$. Considering fully adjusted models, the home PP predicted all of the end points $(P \leqslant 0.044)$, except fatal combined with non-fatal cardiac events $(P=0.052)$ and stroke

Table 2 Standardized hazard ratios relating outcomes to home pulse pressure and mean arterial pressure by age group

\begin{tabular}{|c|c|c|c|c|c|c|c|}
\hline \multirow[b]{3}{*}{ End point } & \multirow[b]{3}{*}{ Model } & \multicolumn{3}{|c|}{ Age $<60$ years } & \multicolumn{3}{|c|}{ Age $\geqslant 60$ years } \\
\hline & & \multirow[b]{2}{*}{$N^{\circ}$ events } & \multicolumn{2}{|c|}{ Hazard ratios } & \multirow[b]{2}{*}{$N^{\circ}$ events } & \multicolumn{2}{|c|}{ Hazard ratios } \\
\hline & & & Mean pressure & Pulse pressure & & Mean pressure & Pulse pressure \\
\hline \multicolumn{8}{|l|}{ Mortality } \\
\hline \multirow[t]{2}{*}{ All causes } & $A$ & 149 & $1.24(1.01-1.51)^{*}$ & $1.28(1.08-1.52)^{\dagger}$ & 663 & $1.04(0.95-1.13)$ & $1.14(1.05-1.25)^{\dagger}$ \\
\hline & FA & & $1.08(0.86-1.37)$ & $1.24(1.01-1.51)^{*}$ & & $0.96(0.86-1.06)$ & $1.17(1.06-1.30)^{\dagger}$ \\
\hline \multirow[t]{2}{*}{ Cardiovascular } & $A$ & 41 & $1.44(0.98-2.10)$ & $1.56(1.15-2.11)^{\dagger}$ & 253 & $1.08(0.94-1.24)$ & $1.22(1.07-1.40)^{\dagger}$ \\
\hline & FA & & $1.15(0.75-1.77)$ & $1.47(1.03-2.10)^{*}$ & & $0.96(0.82-1.14)$ & $1.25(1.06-1.47)^{\dagger}$ \\
\hline \multicolumn{8}{|c|}{ Fatal plus non-fatal events } \\
\hline \multirow[t]{2}{*}{ All cardiovascular } & $A$ & 161 & $1.50(1.24-1.80)^{\S}$ & $1.34(1.15-1.56)^{\S}$ & 555 & $1.26(1.15-1.38)^{\S}$ & $1.25(1.14-1.36)^{\S}$ \\
\hline & $\mathrm{FA}$ & & $1.35(1.09-1.68)^{\dagger}$ & $1.18(0.98-1.41)$ & & $1.18(1.06-1.32)^{\dagger}$ & $1.14(1.02-1.27)^{*}$ \\
\hline \multirow[t]{2}{*}{ Cardiac } & A & 90 & $1.66(1.31-2.10)^{\S}$ & $1.38(1.15-1.66)^{\ddagger}$ & 246 & $1.01(0.88-1.16)$ & $1.12(0.98-1.27)$ \\
\hline & FA & & $1.50(1.12-2.00)^{\dagger}$ & $1.15(0.92-1.45)$ & & $0.91(0.77-1.09)$ & $1.18(1.00-1.39)$ \\
\hline \multirow[t]{2}{*}{ Coronary } & A & 76 & $1.54(1.20-2.00)^{\ddagger}$ & $1.26(1.03-1.55)^{*}$ & 175 & $1.03(0.87-1.21)$ & $1.15(0.99-1.34)$ \\
\hline & FA & & $1.49(1.08-2.06)^{*}$ & $1.05(0.81-1.35)$ & & $0.90(0.73-1.11)$ & $1.22(1.00-1.49)^{*}$ \\
\hline \multirow[t]{2}{*}{ Stroke } & $A$ & 73 & $1.25(0.94-1.68)$ & $1.31(1.01-1.71)^{*}$ & 320 & $1.51(1.34-1.70)^{\S}$ & $1.37(1.21-1.56)^{\S}$ \\
\hline & FA & & $1.13(0.82-1.56)$ & $1.25(0.94-1.68)$ & & $1.42(1.23-1.63)^{\S}$ & $1.14(0.98-1.32)$ \\
\hline
\end{tabular}

Hazard ratios, presented with $95 \%$ confidence interval, express the risk associated with a 1-s.d. (11.7 $\mathrm{mm} \mathrm{Hg}$ and $11.2 \mathrm{~mm} \mathrm{Hg}$ in subjects $<60$ years and $\geqslant 60$ years, respectively) increase in mean home blood pressure or a 1 -s.d. $(8.8 \mathrm{~mm} \mathrm{Hg}$ and $13.4 \mathrm{~mm} \mathrm{Hg})$ increase in home pulse pressure. All models were stratified for cohort and adjusted for sex, age, body mass index, smoking and drinking, serum cholesterol, home pulse rate, diabetes mellitus, history of cardiovascular disease, and antihypertensive treatment. Adjusted models (A) include either the mean blood pressure and drinking, serum cholesterol, home pulse rate, diabetes mellitus, history of cardiovascular disease, and antihypertensive treatment. Adjusted models ( $A$ ) include either the mean blood pressure
or pulse pressure, while fully adjusted models (FA) include both mean blood pressure and pulse pressure in addition to the aforementioned covariates. Significance of the hazard ratios: ${ }^{*} P<0.05$, ${ }^{\dagger} P<0.01,{ }^{\ddagger} P<0.001$, and $\$ P<0.0001$. 
$(P=0.083$; Table 2). Supplementary Table S2 shows the results of a similar analysis using systolic blood pressure instead of mean blood pressure. The generalized $R^{2}$ statistics for adding home PP as a predictor of outcome over and beyond mean arterial pressure was
$0.20 \%$ for cardiovascular mortality and $0.14 \%$ for fatal combined with non-fatal cardiovascular events (Table 3).

Figure 1 shows the multivariable-adjusted HRs comparing the risk in tenths of the distribution of home PP versus the average risk in all

Table 3 Predictive value of the Cox regression models in participants aged 60 or more

\begin{tabular}{|c|c|c|c|c|c|c|c|c|c|c|c|c|}
\hline \multirow[b]{2}{*}{ Models } & \multicolumn{6}{|c|}{ Cardiovascular mortality } & \multicolumn{6}{|c|}{ Cardiovascular events } \\
\hline & $\begin{array}{l}\text { Likelihood } \\
\text { ratio }\end{array}$ & P-value & $\begin{array}{l}\mathrm{R}^{2} \\
(\%)\end{array}$ & $\begin{array}{l}\text { NRI } \\
(\%)\end{array}$ & $\begin{array}{l}|D| \\
(\%)\end{array}$ & $\begin{array}{c}C \\
(\%)\end{array}$ & $\begin{array}{c}\text { Likelihood } \\
\text { ratio }\end{array}$ & P-value & $\begin{array}{l}R^{2} \\
(\%)\end{array}$ & $\begin{array}{l}N R I \\
(\%)\end{array}$ & $\begin{array}{l}|D| \\
(\%)\end{array}$ & $\begin{array}{c}C \\
(\%)\end{array}$ \\
\hline Basic model & 332.3 & $\cdots$ & 9.91 & $\cdots$ & & 52.2 & 327.2 & $\cdots$ & 9.80 & $\cdots$ & $\cdots$ & $\cdots$ \\
\hline Mean home blood pressure added to basic model & 1.2 & 0.27 & 0.03 & 1.11 & -0.20 & 0.04 & 24.8 & $<0.0001$ & 0.70 & 17.6 & 5.6 & 0.92 \\
\hline Systolic home pressure added to basic model & 4.6 & 0.031 & 0.13 & 6.70 & 0.05 & 0.35 & 29.7 & $<0.0001$ & 0.84 & 21.9 & 7.6 & 1.22 \\
\hline Home pulse pressure added to basic model & 8.2 & 0.0042 & 0.23 & 7.81 & 1.50 & 0.74 & 21.2 & $<0.0001$ & 0.60 & 11.1 & 5.9 & 0.96 \\
\hline $\begin{array}{l}\text { Home pulse pressure added to basic model } \\
\text { also including mean blood pressure }\end{array}$ & 7.2 & 0.0074 & 0.20 & 13.4 & 2.50 & 0.74 & 5.0 & 0.026 & 0.14 & 4.3 & 1.8 & 0.31 \\
\hline $\begin{array}{l}\text { Home pulse pressure added to basic model } \\
\text { also including systolic blood pressure }\end{array}$ & 3.7 & 0.053 & 0.11 & 6.31 & 2.25 & 0.44 & 0.00 & 0.96 & 0.00 & 5.9 & -0.0 & 0.00 \\
\hline
\end{tabular}

The basic model included cohort, sex, age, body mass index, smoking and drinking, serum cholesterol, home pulse rate, diabetes mellitus, history of cardiovascular disease and antihypertensive treatment. $P$-values are for the improvement of the fit across nested models. Values are likelihood ratios, generalized $R^{2}$-statistics, net reclassification improvement (NRI), relative integrated discrimination improvement (IDI) and the improvements in Harrell's C statistic (C) by adding mean home blood pressure, home systolic blood pressure or home pulse pressure to the reference model.
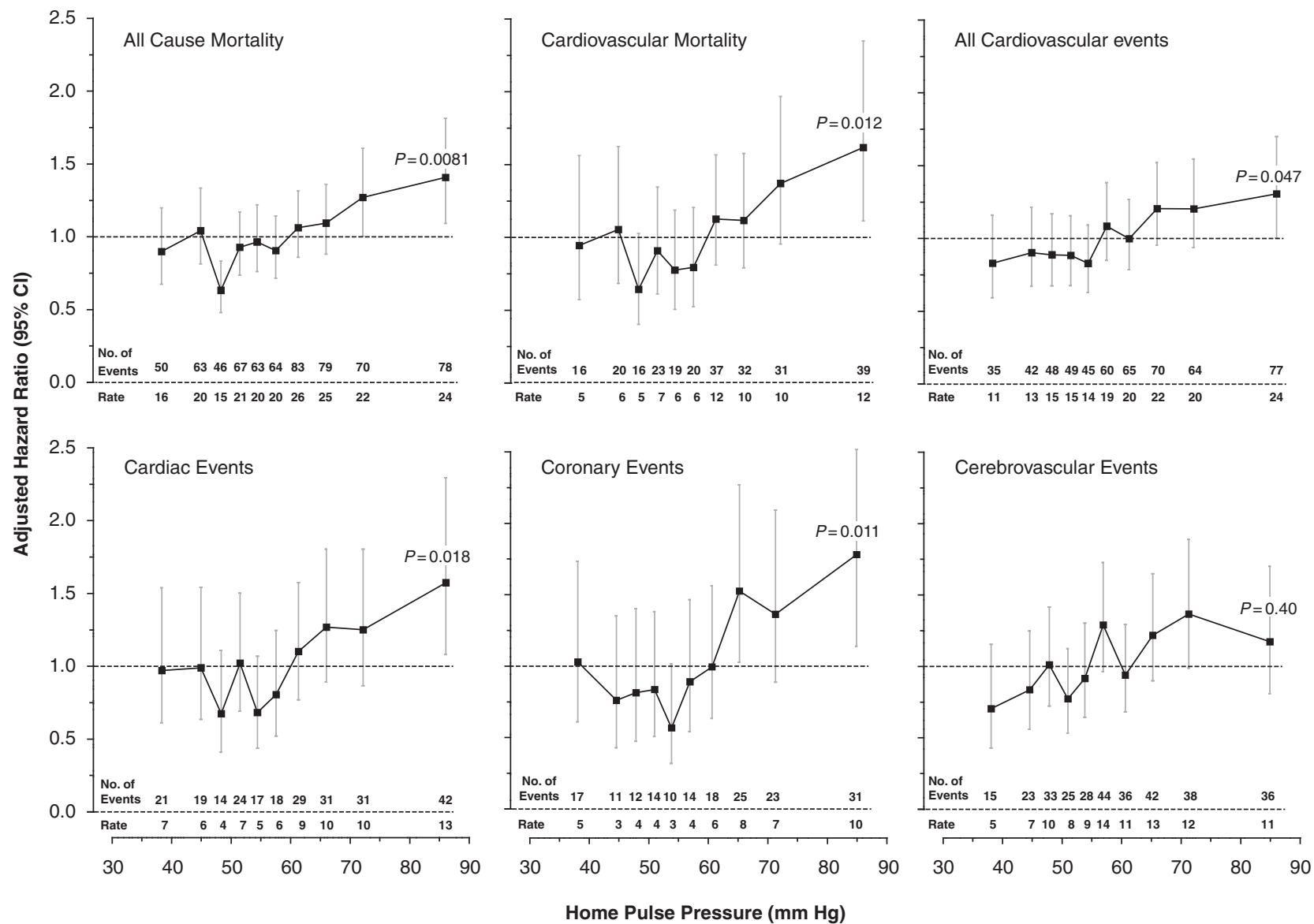

Figure 1 Multivariable-adjusted hazard ratios (95\% confidence intervals) by tenths of the home pulse pressure distribution in 3185 older subjects ( $\geqslant 60$ years). The hazard ratios express the risk in tenths of the distribution compared with the average risk in all elderly and were adjusted for cohort, sex, age, body mass index, smoking and drinking, serum cholesterol, home pulse rate, home mean blood pressure, diabetes mellitus, history of cardiovascular disease and antihypertensive treatment. The number of events and incidence rates (in percent) are also given for each tenth. $P$-values are provided for the hazard ratio in the top tenth. 
Table 4 Standardized hazard ratios for cardiovascular mortality and cardiovascular events in older participants in relation to home pulse pressure in different strata

\begin{tabular}{|c|c|c|c|c|}
\hline Subgroup & At risk (n) & Events (n) & Hazard ratio $(\mathrm{Cl})$ & P-value \\
\hline \multicolumn{5}{|c|}{ Cardiovascular mortality } \\
\hline All participants & 3185 & 253 & $1.25(1.06-1.45)$ & 0.0067 \\
\hline Women & 1809 & 114 & $1.10(0.85-1.43)$ & 0.46 \\
\hline Men & 1376 & 139 & $1.43(1.15-1.77)$ & 0.0014 \\
\hline Hypertension & 1904 & 186 & $1.30(1.08-1.55)$ & 0.0045 \\
\hline Normotension & 1281 & 67 & $1.04(0.62-1.73)$ & 0.89 \\
\hline Treated & 1063 & 125 & $1.21(0.96-1.52)$ & 0.11 \\
\hline Untreated & 2114 & 127 & $1.27(1.01-1.60)$ & 0.044 \\
\hline Whites & 1079 & 74 & $1.04(0.76-1.41)$ & 0.82 \\
\hline Asians & 2106 & 179 & $1.37(1.12-1.68)$ & 0.0022 \\
\hline \multicolumn{5}{|c|}{ Fatal and non-fatal cardiovascular events } \\
\hline All participants & 3185 & 555 & $1.14(1.02-1.27)$ & 0.025 \\
\hline Women & 1809 & 252 & $1.03(0.87-1.23)$ & 0.71 \\
\hline Men & 1376 & 303 & $1.23(1.06-1.42$ & 0.0069 \\
\hline Hypertension & 1904 & 410 & $1.15(1.01-1.30)$ & 0.032 \\
\hline Normotension & 1281 & 145 & $1.24(0.89-1.74)$ & 0.21 \\
\hline Treated & 1063 & 262 & $1.08(0.92-1.27)$ & 0.33 \\
\hline Untreated & 2114 & 291 & $1.17(1.00-1.36)$ & 0.057 \\
\hline Whites & 1079 & 197 & $1.01(0.83-1.22)$ & 0.91 \\
\hline Asians & 2106 & 358 & $1.21(1.05-1.40)$ & 0.0087 \\
\hline
\end{tabular}

Hazard ratios (95\% confidence intervals (Cls) were calculated in subjects $\geqslant 60$ years and express the risk associated with a 1-s.d. $(13.1 \mathrm{~mm} \mathrm{Hg})$ increase in home pulse pressure. All models were stratified for cohort and adjusted for sex, age, body mass index, smoking and drinking, serum cholestel, home pulse rate and mean blod pressure, dia, smoking and history of cardiovascular disease and antihypertensive treatment. Hazard ratios did not diffe significantly between subgroups $(P>0.19)$. Whites were recruited in Didima, Finland and Montevideo and Asians in Ohasama and Sendai.

of the elderly. The HRs reached statistical significance in the ninth (1.27; CI, 1.00-1.61; $P=0.046)$ and in the upper (1.41; CI, 1.09-1.81; $P=0.0081)$ tenths for total mortality, and in the upper tenth for cardiovascular mortality (1.62; CI, $1.11-2.35 ; P=0.012)$, all cardiovascular events $(1.31 ; \mathrm{CI}, 1.00-1.70 ; P=0.047)$, all cardiac events (1.57; 1.08-2.30; $P=0.018)$ and all coronary events (1.78; CI, 1.142.78; $P=0.011)$. The risk of stroke in the upper tenth did not exceed the average risk among all elderly (HR, 1.17; CI, 0.81-1.70; $P=0.40$ ). $\mathrm{PP}$ in the ninth and top tenth of the distribution of home PP averaged $71.3 \mathrm{~mm} \mathrm{Hg}$ (range, 67.8-75.9 $\mathrm{mm} \mathrm{Hg}$ ) and $84.9 \mathrm{~mm} \mathrm{Hg}$ (range, 76.0$125.8 \mathrm{~mm} \mathrm{Hg})$.

Sensitivity analyses. We checked the consistency of our results for cardiovascular mortality and for fatal and non-fatal cardiovascular events combined (Table 4), according to various baseline characteristics in older participants. The HRs expressing the risk associated with a 1-s.d. (13.1 $\mathrm{mm} \mathrm{Hg})$ increase in home PP were not statistically different between subgroups $(0.19 \leqslant P \leqslant 0.93)$. In addition, our results did not materially change after excluding one cohort at a time. Finally, we repeated our analyses using tenths of the distribution of the conventionally measured PP instead of home PP. PP in the top tenth of the distribution of the conventionally measured PP averaged $90.6 \mathrm{~mm} \mathrm{Hg}$ (range, $81.0-159.0 \mathrm{~mm} \mathrm{Hg}$ ). With adjustments applied as before, this level of conventional PP was associated with increased total mortality (HR, 1.36; CI, 1.10-1.70; $P=0.006$ ), but not with excess cardiovascular mortality (HR, 1.21; CI, 0.86-1.71; $P=0.27)$, or cardiovascular (HR, 1.06; CI, 0.83-1.36; $P=0.63)$ or cardiac $(\mathrm{HR}$, 1.13; CI, 0.79-1.63; $P=0.49)$ events.

\section{DISCUSSION}

To our knowledge, our current study provides the first populationbased findings on the incremental value of self-measured PP in the prediction of mortality and cardiovascular events over and beyond traditional risk factors, including mean arterial pressure, the steady component of blood pressure. ${ }^{5}$ Below age 60 , home PP predicted allcause and cardiovascular mortality. From age 60 onwards, home PP predicted total and cardiovascular mortality and all cardiovascular and coronary events. In the elderly, a PP of $\geqslant 76 \mathrm{~mm} \mathrm{Hg}$ was associated with adverse cardiovascular outcomes, but not including stroke. However, PP did not substantially refine risk prediction based on classical risk factors including mean arterial pressure.

The only prior outcome-based population study reporting on the predictive value of self-measured PP was the Ohasama study. ${ }^{11,30}$ Among 2369 subjects without a history of stroke (mean age, 59 years; $60 \%$ women), 238 strokes occurred during 11.7 years of follow-up. ${ }^{11}$ In line with our current findings, PP was a weaker predictor of stroke than mean arterial pressure. ${ }^{11}$ Among 1913 Ohasama participants, followed up for 8.3 years, 93 died because of cardiovascular disease. ${ }^{30}$ Each $10 \mathrm{~mm} \mathrm{Hg}$ increment in the home PP was associated with a higher risk of cardiovascular mortality (HR, 1.37; CI, 1.14-1.55; $P=0.001) .{ }^{30}$ The analysis focusing on stroke was adjusted for sex, age, smoking, use of antihypertensive medication, hypercholesterolemia, diabetes mellitus and history of heart disease. ${ }^{11}$ The analysis of cardiovascular mortality was adjusted for the same covariables plus obesity. ${ }^{30}$ Obesity was a body mass index exceeding $25.0 \mathrm{~kg} \mathrm{~m}^{-2}$, not $30 \mathrm{~kg} \mathrm{~m}^{-2}$, and the overall prevalence was $20.5 \%$, which seems to be higher than expected for Japanese. The Ohasama results are not representative for other ethnicities and were not adjusted for body mass index, home pulse rate and drinking status. However, our current study that includes $48.5 \%$ Whites and the Ohasama results ${ }^{11,30}$ are consistent with the concept that $\mathrm{PP}$, representing the pulsatile component of blood pressure, is the dominant predictor of cardiac events, ${ }^{31}$ whereas mean arterial pressure, representing the steady component of blood pressure, is the dominant predictor of stroke. ${ }^{6,32}$

Several longitudinal population studies ${ }^{19-21,33}$ attempted to establish cardiovascular prognosis and diagnostic cutoff limits for blood pressure components derived from home-based measurements. However, up to this day, they did not address outcome-driven thresholds for home PP. To our knowledge, the PARTAGE (Predictive Values of Blood Pressure and Arterial Stiffness in Institutionalized Very Aged Population) $s^{2} u d y^{34}$ is the only study that reported on the 2-year predictive value of the self-measured PP in a cohort of patients. The study included 1126 very old participants (77.6\% women; mean age, 88 years), who were living in French and Italian nursing homes. At baseline, participants measured their blood pressure following the 'rule of 3' (three measurements with intervals of $1 \mathrm{~min}$ in the morning and evening for 3 consecutive days). During follow-up, 247 participants died and 228 experienced a major cardiovascular event. The self-measured PP averaged $65 \mathrm{~mm} \mathrm{Hg}$, but was not a significant predictor either of total mortality (HR for $+10 \mathrm{~mm} \mathrm{Hg}, 0.90$; CI, $0.81-1.00 ; P=0.057)$ or of cardiovascular events (HR, 0.98; CI, 0.89-1.09; $P=0.74$ ). Several cross-sectional studies in patients addressed the association between intermediate signs of target organ damage and PP. However, results obtained in patients, in particular from cross-sectional studies, are not representative of populations and are not relevant to the research question addressed in our current manuscript.

The Seventh Report of the Joint National Committee on Prevention, Detection, Evaluation, and Treatment of High Blood Pressure ${ }^{12}$ 
proposed that PP is only marginally stronger than systolic blood pressure for risk stratification in individuals over age 60, and that under age 60, PP is not predictive. The 2007 European guideline ${ }^{35}$ stated that PP is a derived measure, which combines the imprecision of the original systolic and diastolic measurements and that, although levels of 50-55 $\mathrm{mm} \mathrm{Hg}$ have been suggested, no practical cutoff values separating PP normality from abnormality were available. The 2013 European guideline ${ }^{13}$ increased this threshold to $60 \mathrm{~mm} \mathrm{Hg}$ without any justification. Our current analyses established that below age 60 , total and cardiovascular mortality were log linearly associated with home PP, but that due to the small number of events no outcomedriven threshold could be established. In the elderly, home PP predicted all end points with the exception of stroke, but the refinement of prognostication over and beyond traditional risk factors and the steady component of blood pressure was small. Among elderly, the threshold delineating increased risk of death is around $68 \mathrm{~mm} \mathrm{Hg}$ and for fatal combined with non-fatal cardiovascular events $76 \mathrm{mmHg}$. Using the same approach for conventional PP in elderly participants identified a threshold of around $91 \mathrm{~mm} \mathrm{Hg}$ for an increased risk of cardiovascular complications.

The current sensitivity analysis showed that home PP was a significant predictor of cardiovascular mortality and cardiovascular events in Asians but not in Whites. However, the HRs were not significantly different between the two races (Table 4) indicating that this finding might be due to chance.

The strong points of our current report are the relatively large sample size and the large number of events, which occurred over a median follow-up of $>8$ years. However, our current results must also be interpreted within the context of their potential limitations. First, the anthropometric characteristics and the time of recruitment within the IDHOCO database differed between cohorts, and clinic and home BP measurements were not standardized in terms of device type, number of measurements and intervals between readings. Second, our analysis rested on five population-based cohorts with an overrepresentation of Asians and Caucasians, and might not be representative for other ethnic groups, in particular Blacks. Third, for a limited number of covariables, we used interpolated data. However, sensitivity analyses from which we excluded the Didima cohort were confirmatory. Finally, the generalized $R^{2}$ is not a perfect measure of the variation explained by Cox models. Nevertheless, a measure of explained variance is essential for the correct interpretation of the prognostic value of a risk factor, because $P$-values of HRs do not necessarily reflect clinical significance.

In conclusion, home PP adds little information on cardiovascular outcomes below age 60 based on our observations in randomly recruited people. In the elderly, home PP is a weak risk factor with levels below $68 \mathrm{~mm} \mathrm{Hg}$ probably being innocuous. However, using this threshold in clinical practice might be of little value, because home PP does not substantially enhance risk stratification over and beyond the steady component of the blood pressure level and other cardiovascular risk factors. Our current findings might inform future guidelines and lead to a consensus about a threshold for PP that is justified by health outcomes.

\section{CONFLICT OF INTEREST}

The authors declare no conflict of interest.

\section{ACKNOWLEDGEMENTS}

We gratefully acknowledge the expert assistance of José Alfie, Marcelo Rada, Margarita Morales and Carlos R Galarza (Sección Hipertensión Arterial,
Servicio de Clinica Médica, Hospital Italiano de Buenos Aires, Argentina) and of Sandra Covens and Annick De Soete (Studies Coordinating Centre, Leuven, Belgium). This study was supported by the European Union (grants IC15CT98-0329-EPOGH, LSHM-CT-2006-037093 InGenious HyperCare, HEALTH-F4-2007-201550 HyperGenes, HEALTH-F7-2011-278249 EUMASCARA, HEALTH-F7-305507 HOMAGE and the European Research Council Advanced Research Grant 294713 EPLORE) and the Fonds voor Wetenschappelijk Onderzoek Vlaanderen, Ministry of the Flemish Community, Brussels, Belgium (G.0734.09, G.0881.13 and G.088013N) supported the Studies Coordinating Centre (Leuven, Belgium). The Ohasama study was supported by the Grants for Scientific Research (23249036, 23390171, 24591060, 24390084, 24591060, 22590767, 22790556, 23790718, 23790242 and 24790654) from the Ministry of Education, Culture, Sports, Science, and Technology, Japan; Health Labour Sciences Research Grant (H23Junkankitou [Seishuu]-Ippan-005) from the Ministry of Health, Labour and Welfare, Japan; the Japan Arteriosclerosis Prevention Fund; and the Grant from the Daiwa Securities Health Foundation. The Finn-Home project organization created for the study involved the Finnish Center for Pensions, Social Insurance Institution, National Public Health Institute, Local Government Pensions Institution, National Research and Development Center for Welfare and Health, Finnish Dental Society and the Finnish Dental Association, Statistics Finland, Finnish Work Environment Fund, Finnish Institute for Occupational Health, UKK Institute for Health Promotion, State Pensions Office, and State Work Environment Fund. The Asociación Española Primera de Socorros Mutuos, the Agencia Nacional de Investigación e Innovación and Gramón-Bagó supported the Montevideo study. The Tsurugaya study was supported by a Health Sciences Research Grant for Health Service (H21Choju-Ippan-001) from the Ministry of Health, Labor and Welfare, Japan, and the Japan Arteriosclerosis Prevention Fund. The Buenos Aires study was supported by the Hospital Italiano de Buenos Aires, Servicio de Clínica Médica, Argentina.

1 Staessen J, Amery A, Fagard R. Editorial review. Isolated systolic hypertension. J Hypertens 1990; 8: 393-405.

2 Bangalore S, Messerli FH, Franklin SS, Mancia G, Champion A, Pepine CJ. Pulse pressure and risk of cardiovascular outcomes in patients with hypertension and coronary artery disease : an INternational VErapamil SR-trandolapril STudy (INVEST) analysis. Eur Heart J 2009; 30: 1395-1401.

3 Amar J, Vernier I, Rossignol E, Bongard V, Arnaud C, Conte JJ, Salvador M, Chamontin B. Nocturnal blood pressure and 24-hour pulse pressure are potent indicators of mortality in hemodialysis patients. Kidney Int 2000; 57: 2485-2491.

4 Liu JH, Chen CC, Wang SM, Chou CY, Liu YL, Kuo HL, Lin HH, Wang IK, Yang YF, Huang CC. Association between pulse pressure and 30-month all-cause mortality in peritoneal dialysis patients. Am J Hypertens 2008; 21: 1318-1323.

5 Darne B, Girerd X, Safar M, Cambien F, Guize L. Pulsatile versus steady component of blood pressure : a cross-sectional analysis and a prospective analysis on cardiovascular mortality. Hypertension 1989; 13: 392-400.

6 Benetos A, Safar M, Rudnichi A, Smulyan H, Richard JL, Ducimetiere P, Guize L. Pulse pressure: a predictor of long-term cardiovascular mortality in a French male population. Hypertension 1997; 30: 1410-1415.

7 Borghi C, Dormi A, Ambrosioni E, Gaddi A on behalf of the Brisighella Heart Study working party. Relative role of systolic, diastolic and pulse pressure as risk factors for cardiovascular events in the Brisighella Heart Study. J Hypertens 2002; 20: 1737-1742.

8 Schram MT, Kostense PJ, van Dijk RAJM, Dekker JM, Nijpels G, Bouter LM, Heine RJ, Stehouwer CDA. Diabetes, pulse pressure and cardiovascular mortality: the Hoorn Study. J Hypertens 2002; 20: 1743-1751.

9 Glynn RJ, Chae CU, Guralnik JM, Taylor JO, Hennekens $\mathrm{CH}$. Pulse pressure and mortality in older people. Arch Intern Med 2000; 160: 2765-2772.

10 Staessen JA, Thijs L, Ohkubo T, Kikuya M, Richart T, Boggia J, Adiyaman A, Dechering DG, Kuznetsova T, Thien T, de Leeuw P, Imai Y, O'Brien E, Parati G. Thirty years of research on diagnostic and therapeutic thresholds for the self-measured blood pressure at home. Blood Press Monit 2008; 13: 352-365.

11 Inoue R, Ohkubo T, Kikuya K, Metoki H, Asayama K, Kanno A, Obara T, Hirose T, Hara A, Hoshi H, Totsune K, Satoh H, Kondo Y, Imai Y. Stroke risk of blood pressure Indices determined by home blood pressure measurement: the Ohasama Study. Stroke 2009; 40: 2859-2861.

12 Chobanian AV, Bakris GL, Black HR, Cushman WC, Green LA, Izzo JL Jr, Jones DW, Materson BJ, Oparil S, Wright JT Jr, Roccella EJ the National High Blood Pressure Education Program Coordinating Committee. Seventh report of the Joint National Committee on Prevention, Detection, Evaluation, and Treatment of High Blood Pressure. Hypertension 2003; 42: 1206-1252. 
13 Mancia G, Fagard R, Narkiewicz K, Redon J, Zanchetti A, Bohm M, Christiaens T, Cifkova R, De BG, Dominiczak A, Galderisi M, Grobbee DE, Jaarsma T, Kirchhof P, Kjeldsen SE, Laurent S, Manolis AJ, Nilsson PM, Ruilope LM, Schmieder RE, Sirnes PA, Sleight P, Viigimaa M, Waeber B, Zannad F. 2013 ESH/ESC Guidelines for the management of arterial hypertension: the task force for the management of arterial hypertension of the European Society of Hypertension (ESH) and of the European Society of Cardiology (ESC). J Hypertens 2013; 31: 1281-1357.

14 Niiranen TJ, Asayama K, Thijs L, Johansson JK, Ohkubo T, Kikuya M, Boggia J, Hozawa A, Sandoya E, Stergiou GS, Tsuji I, Jula AM, Imai Y, Staessen JA for the Database of HOme blood pressure in relation to Cardiovascular Outcome Investigators. Outcome-driven thresholds for home blood pressure measurement: International Database for HOme blood pressure in relation to Cardiovascular Outcome. Hypertension 2013; 61: 27-34.

15 Cacciolati C, Tzourio C, Dufouil C, Alperovitch A, Hanon O. Feasibility of home blood pressure measurement in elderly individuals: cross-sectional analysis of a populationbased sample. Am J Hypertens 2012; 25: 1279-1285.

16 Barochiner J, Cuffaro PE, Aparicio LS, Elizondo CM, Giunta DH, Rada MA, Morales MS, Alfie J, Galarza CR, Waisman GD. Reproducibility and reliability of a 4 day HBPM protocol with and without first day measurements. Rev Fac Cien Med Univ Nac Cordoba 2011; 68: 149-153.

17 Ohkubo T, Imai Y, Tsuji I, Nagai K, Kato J, Kikuchi N, Nishiyama A, Aihara A, Sekino M, Kikuya M, Ito S, Satoh H, Hisamichi S. Home blood pressure measurement has a stronger predictive power for mortality than does screening blood pressure measurement : a population-based observation in Ohasama, Japan. J Hypertens 1998; 16: $971-975$.

18 Niiranen TJ, Thijs L, Asayama K, Johansson JK, Ohkubo T, Kikuya M, Boggia J, Hozawa A, Sandoya E, Stergiou GS, Tsuji I, Jula AM, Imai Y, Staessen JA on behalf of the IDHOCO investigators. The International Database of HOme blood pressure in relation to Cardiovascular Outcome (IDHOCO): moving from baseline characteristics to research perspectives. Hypertens Res 2012; 35: 1072-1079.

19 Niu K, Hozawa A, Awata S, Guo H, Kuriyama S, Seki T, Ohmori-Matsuda K, Nakaya N Ebihara S, Wang Y, Tsuji I, Nagatomi R. Home blood pressure is associated with depressive symptoms in an elderly population aged 70 years and over : a populationbased, cross-sectional analysis. Hypertens Res 2008; 31: 409-416.

20 Schettini C, Bianchi M, Nieto F, Sandoya E, Senra H, Hypertension Working Group. Ambulatory blood pressure. Normality and comparison with other measurements. Hypertension 1999; 34: 818-825.

21 Stergiou GS, Baibas NM, Kalogeropoulos PG. Cardiovascular risk prediction on home blood pressure measurement: the Didima Study. J Hypertens 2007; 25: 1590-1596.

22 Expert Committee on the Diagnosis and Classification of Diabetes Mellitus. Report of the expert committee on the diagnosis and classification of diabetes mellitus. Diabetes Care 2003; 26(suppl 1): S5-S20.

23 Panagiotakos DB, Pitsavos C, Lentzas Y, Chrysohoou C, Stefanadis C. Five-year incidence of hypertension and its determinants: the ATTICA study. J Hum Hypertens 2007: 21: 686-688.

24 Madianos MG, Gefou-Madianou D, Stefanis C. Patterns of alcohol consumption and related problems in the general population. Addiction 1995; 90: 73-85.
25 Franklin SS, Larson MG, Khan SA, Wong ND, Leip EP, Kannel WB, Levy D. Does the relation of blood pressure to coronary heart disease change with aging? The Framingham Heart Study. Circulation 2001; 103: 1245-1249.

26 Hosmer DW Jr, Leleshow S. Applied Logistic Regression. John Wiley \& Sons, New York, 1989; 47-56.

27 Cook NR, Ridker PM. Advances in measuring the effect of individual predictors of cardiovascular risk: the role of reclassification measures. Ann Intern Med 2009; 150. 795-802.

28 Harrell FE, Lee KL, Mark DB. Multivariable prognostic models: issues in developing models, evaluating assumptions and adequacy, and measuring and reducing numbers. Stat Med 1996; 15: 361-387.

29 Gillespie BW. Use of generalized R-squared in Cox regression http://apha.confex.com/ apha/134am/techprogram/paper_135906.htm. APHA Scientific Session and Event Listing 2006

30 Hozawa A, Ohkubo T, Nagai K, Kikuya K, Matsubara M, Tsuji I, Sadayoshi I, Satoh H Hisamichi S, Imai Y. Prognosis of isolated systolic hypertension and isolated diastolic hypertension as assessed by self-measurement of blood pressure at home. The Ohasama Study. Arch Intern Med 2000; 160: 3301-3306.

31 Blacher J, Staessen JA, Girerd X, Gasowski J, Thijs L, Liu L, Wang JG, Fagard RH, Safar ME. Pulse pressure not mean pressure determines cardiovascular risk in older hypertensive patients. Arch Intern Med 2000; 160: 1085-1089.

32 Verdecchia P, Schillaci G, Reboldi G, Franklin SS, Porcellati C. Different prognostic impact of 24-hour mean blood pressure and pulse pressure on stroke and coronary artery disease in essential hypertension. Circulation 2001; 103 : 2579-2584.

33 Niiranen TJ, Hanninen MR, Johansson J, Reunanen A, Jula A. Home-measured blood pressure is a stronger prediictor of cardiovascular risk than office blood pressure : the Finn-Home Study. Hypertension 2010; 55: 1351.

34 Benetos A, Gautier S, Labat C, Salvi P, Valbusa F, Marino F, Toulza O, Agnoletti D, Zamboni M, Dubail D, Manckoundia P, Rolland Y, Hanon O, Perret-Guillaume C, Lacolley P, Safar ME, Guillemin F. Mortality and cardiovascular events are best predicted by low central/peripheral pulse pressure amplification but not by high blood pressure levelsin elderly nursing home subjects. J Am Coll Cardiol 2012; 60: 1503-1511.

35 Mancia G, De Backer G, Dominiczak A, Cifkova R, Fagard R, Germano G, Grassi G, Heagerty AM, Kjeldsen SE, Laurent S, Narkiewicz K, Ruilope L, Rynkiewicz A Schmieder RE, Struijker-Boudier HA, Zanchetti A, Vahanian A, Camm J, De Caterina R, Dean V, Dickstein K, Filippatos G, Funck-Brentano C, Hellemans I, Kristensen SD, McGregor K, Sechtem U, Silber S, Tendera M, Widimsky P, Zamorano JL, Erdine S, Kiowski W, Agabiti-Rosei E, Ambrosioni E, Lindholm LH, Manolis A, Nilsson PM, Redon J, Struijker-Boudier HA, Viigimaa M, Adamopoulos S, Bertomeu V, Clement D, Farsang C, Gaita D, Lip G, Mallion JM, Manolis AJ, O'Brien E, Ponikowski P, Ruschitzka F, Tamargo J, van Zwieten P, Waeber B, Williams B. 2007 guidelines for the management of arterial hypertension: the task force for the management of arterial hypertension of the European Society of Hypertension (ESH) and of the European Society of Cardiology (ESC). Eur Heart J 2007; 28: $1462-1536$.

Supplementary Information accompanies the paper on Hypertension Research website (http://www.nature.com/hr) 